\title{
Implementasi Algoritme Bellman-Ford dalam Menentukan Rute Terpendek Pembuangan Sampah Di Kota Kendari
}

\author{
Ma'arif ${ }^{1) *}$, Maoudy Bastutiar Mhadjid ${ }^{2)}$, M. Syadam Purwanto ${ }^{3)}$ \\ 1)* Jurusan Matematika MIPA, Universitas Halu Oleo \\ ${ }^{2,3)}$ Jurusan Matematika MIPA, Universitas Halu Oleo \\ *Korespondensi Author Email: youngauthorkendari@gmail.com
}

\begin{abstract}
Abstrak: Berbagai masalah muncul diantaranya kurangnya fasilitas pengangkut sampah yang diberikan oleh pemerintah kepada dinas terkait, sehingga pengangkutan sampah dari Tempat Penampungan Sementara (TPS) sampai ke Tempat Pembuangan Akhir (TPA) tidak optimal dalam pelaksanaanya. Tujuan dari kajian ini adalah untuk menerapkan Algoritme Bellman- Ford dalam penentuan rute terpendek pengangkutan sampah dari TPS ke TPA di Kota Kendari. Tahapan Algoritme Bellman-Ford dimulai dari tahap analisis kebutuhan data, perancangan, implementasi, dan pengujian. Sedangkan data yang digunakan pada kajian ini berupa data primer dan data sekunder tentang lintasan pengangkutan sampah dari TPS ke TPA yang ada di Kota Kendari. Perhitungan koordinat akan dihitung menggunakan konsep graf dan haversine formula berantuan Global Positioning System (GPS). Data hasil analisis berupa simpul yang merepresentasikan TPS yang ada di Kota Kendari, sedangkan sisi merepresentasikan lintasan yang menghubungkan antar TPS ke TPA. Sedangkan bobot merepresentasikan jarak (km) antar TPS dan TPA. Algoritme Bellman-Ford memungkinkan adanya bobot yang negatif untuk nilai edge-nya, sehingga dapat mengantisipasi kemungkinan adanya cost yang harus dikeluarkan dalam pemilihan jalur pengambilan sampah. Dampak dari penelitian ini yaitu dapat diketahuinya jalur tercepat dan terpendek pembuangan sampah ke tempat pembuangan akhir di Kota Kendari.
\end{abstract}

Kata Kunci: Algoritme Bellman-Ford; pembuangan sampah; rute terpendek

\begin{abstract}
Various problems arise, including the lack of waste transportation facilities provided by the government to related agencies, so that the transportation of waste from the Temporary Storage (TPS) to the Final Disposal Site (TPA) is not optimal in its implementation. The purpose of this study is to apply the Bellman-Ford Algorithm in determining the shortest route for transporting waste from TPS to TPA in Kendari City. The Bellman-Ford algorithm stages start from the data requirements analysis, design, implementation, and testing stages. Meanwhile, the data used in this study are primary data and secondary data on the route of transporting waste from TPS to TPA in Kendari City. The calculation of coordinates will be calculated using the graph concept and the haversine formula based on the Global Positioning System (GPS). The data from the analysis are in the form of nodes that represent the TPS in Kendari City, while the sides represent the paths that connect between TPS and TPA. While the weight represents the distance $(\mathrm{km})$ between TPS and TPA. The Bellman-Ford algorithm allows a negative weight for the edge value, so as to anticipate the possible costs involved in selecting the waste collection path. The impact of this research is to find out the fastest and shortest paths for dumping waste to landfills in Kendari City.
\end{abstract}

Keywords: Algoritme Bellman-Ford; Garbage disposal; Shortest route

\section{PENDAHULUAN}

Berdasarkan peraturan Menteri Pekerjaan Umum (Pemen PU) Nomor : 21/PRT/M/2006 untuk mencapai kondisi masyarakat yang sehat dan sejahtera di masa yang akan datang, akan sangat diperlukan adanya lingkungan permukiman yang sehat. Kata sehat akan berarti sebagai kondisi yang akan dapat dicapai bila keadaan air, udara, dan tanah bersih dari sampah maupun polusi. Sampah dapat dikelola secara baik sehingga bersih dari lingkungan permukiman dimana manusia beraktifitas di dalamnya.

Sampah pada umumnya merupakan permasalahan yang menjadi fokus utama di kota-kota besar di
Indonesia, salah satunya yang terdapat di Kota Kendari. Permasalahan utamanya adalah kurang optimalnya pengangkutan sampah yang dilakukan, sehingga membuat sampah yang berada di tempat penampungan sementara tidak terangkut secara keseluruhan. Selain itu, berbagai faktor lainnnya adalah kurangnya optimalisasi pengangkutan sampah juga disebabkan karena kurangnya fasilitas TPS yang disediakan dan jalur pengangkutan yang jauh dalam pengangkutan sampah untuk menuju TPA (Prasetyo, 2017). Hal ini mengakibatkan keterbatasan waktu operasional dan jarak pembuangan sampah yang sangat relatif besar (Aji, 2017). Oleh karena itu, diperlukan sebuah solusi alternatif dalam membuat 
sebuah rute yang efektif dan efisien dalam proses pengangkutan sampah. Salah satunya yaitu dengan menggunakan Algoritme Bellman-Ford. Algoritme Bellman-Ford merupakan sebuah sistem algoritma yang digunakan untuk pencarian rute terpendek dalam sebuah lintasan (Lestari, 2018; Radiana, 2015). Selama ini Algoritme Bellman-Ford hanya digunakan dalam pemetaan sistem informasi dan pemetaan protocol system dalam sebuah sistem telekomunikasi (Pramudita\& Safitri, 2018; Sulaiman dkk. 2018). Akan tetapi, kajian terbaru yang dilakukan oleh Azdy \& Darnis (2019) berhasil mengimplementasikan dan membuat jalur terpendek pembuangan sampah di Kota Palembang dengan menggunakan Algoritme Bellman-Ford.

Kajian ini pun menggunakan konsep graf dalam penyelesaiannya, secara geometri graf digambarkan sebagai sekumpulan noktah (simpul) di dalam bidang dwimatra yang dihubungkan dengan sekumpulan garis (sisi) (Nugraha, 2011; Munir, 2009). Algoritma BellmanFord ini dikenal dengan kelebihan dalam menangani kasus-kasus graf berbobot negatif jika dibandingkan dengan algoritma-algoritma lainnya (Yudi, 2009; Hamdi \& Prindahoko, 2018). Penelitian ini bertujuan utuk Untuk menentukan rute terpendek pada pemodelan jaringan rute pengangkutan sampah di wilayah Kota Kendari (Kecamatan Puuwatu) dari TPS menuju ke TPA Puuwatu dan Mengetahui hasil perbandingan rute pengangkutan sampah yang selama ini diterapkan oleh Dinas Lingkungan Hidup Kota Kendari dengan rute pangangkutan sampah menggunakan perhitungan Algoritme Bellman-Ford.

\section{METODE}

Jenis penelitian yang digunakan adalah studi kasus yang bertujuan untuk mengumpulkan informasi (Daniel \& Prida, 2019) yaitu nama-nama jalan yang ada di kecamatan Puuwatu, kemudian menentukan jarak antara setiap batas-batas jalan dengan menggunakan aplikasi Mapit GIS. Kemudian diselesaikan dengan menggunakan Algoritma Bellman-Ford. Rancanga penelitian menggunakan Studi literatur, yaitu membahas dan menjabarkan serta mengaitkan konsep- koensep yang sudah ada di dalam tinjauan pustaka. Studi lapangan, yaitu dengan meneliti langsung rute truk pengangkut sampah di Kecamatan Puuwatu sehingga didapat rute yang efisien. penelitian dilakukan di Kecamatan Puuwatu.

Selanjutnya prosedur penelitian dilakukan sebagai berikut. Melakukan pengumpulan data Pengumpulan data diperoleh dari internet menggunakan aplikasi Mapit GIS dan dari kepala Dinas Lingkungan Hidup Kota Kendari. Mencari jalur minimum truk sampah pada kecamatan Puuwatu ke tempat pembuangan akhir (TPA) dengan menggunakan metode Algoritma Bellmand-Ford secara manual.

Langkah-langkahnya yaitu sebagai berikut: (a.) Menentukan titik asal dan mendaftar semua titik maupun sisi. (b).Memberi nilai untuk titik asal sama dengan nol dan titik-titik lainnya dengan tak hingga. (c).Memulai iterasi terhadap semua titik yang ada dimulai dengan titik asal, untuk menentukan jarak dari semua titik yang berhubungan dengan titik asal dengan formula seperti berikut: $\mathrm{U}=$ titik asal, $\mathrm{V}=$ titik tujuan, $\mathrm{UV}=$ sisi yang menghubungkan $\mathrm{U}$ dan $\mathrm{V}$. Jika jarak $\mathrm{V}$ lebih besar dari jarak U + bobot UV maka jarak $\mathrm{V}$ diisi dengan jarak U+bobot UV, dilakukan hingga semua titik terjelajahi. Mencari jalur minimum truk sampah menggunakan Algoritma Bellmand-Ford.

\section{HASIL DAN PEMBAHASAN}

Berdasarkan investigasi yang dilakukan dengan menggunakan aplikasi Google Maps dan Mapit GIS, diperoleh peta serta jarak antar jalan di kecamatan Puuwatu. Tahapan tersebut adalah sebagai berikut.

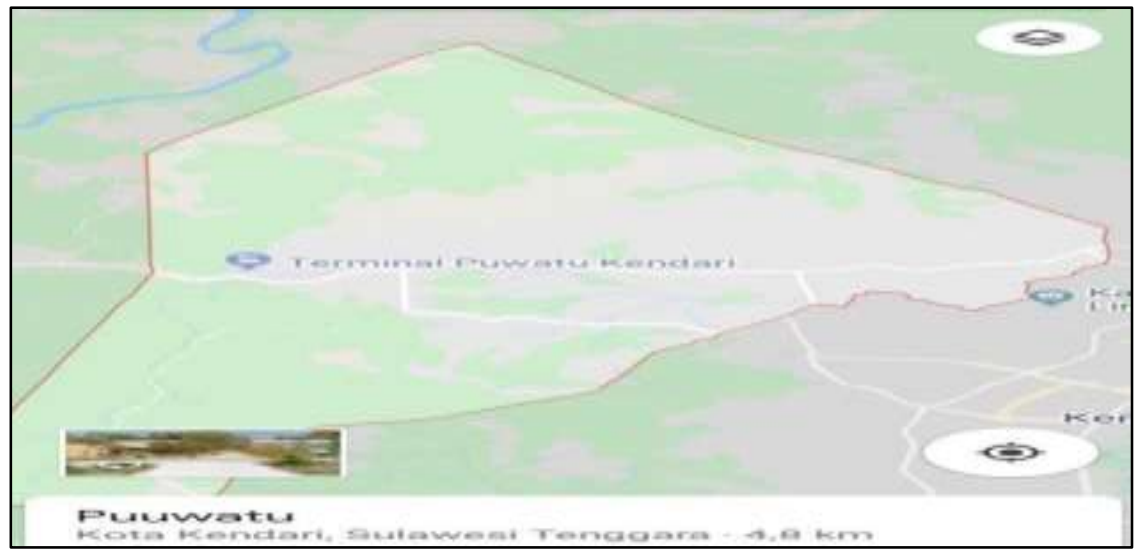

Gambar 1. Peta Kecamatan Puuwatu 
Berdasarkan penelitian yang dilakukan dengan menggunakan aplikasi Google Maps dan Mapit GIS, diperoleh peta kecamatan Puuwatu. Peta kecamatan Puuwatu yang dijadikan sampel dalam penelitian ini

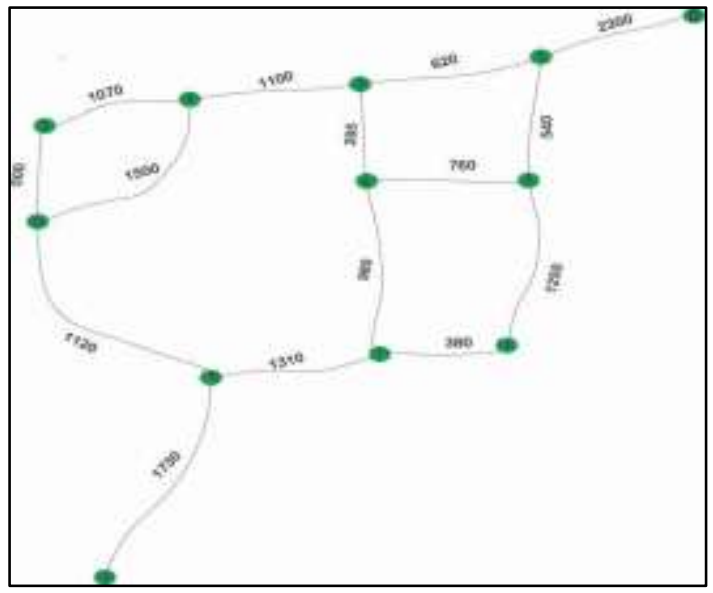

Gambar 2. Graf Rute Jalan Kecamatan Puwatu

\section{Keterangan :}

Titik 0-2 - 5 : Jl. Raden Soeprapto; Titik 2-3-4 : Jl. H. Latama Bunggulawa; Titik 5-6- 7 : Jl. Banda; Titik

Pada Gambar 2. terdapat 12 titik. Titik tersebut merupakan batas- batas jalan, dimana titik 0 merupakan titik awal. Data jalan yang digunakan untuk mengetahui jalur terpendek dari rute truk pengangkutan sampah ke semua titik batas jalan. Satuan yang digunakan dalam penelitian ini adalah meter (m). Berdasarkan hasil wawancara dengan Kepala Dinas Lingkungan Hidup Kota Kendari bahwa rute yang biasa diterapakan oleh truk pengangkut sampah menuju ketempat pembuangan akhir (TPA) yaitu sebagai berikut. Mencari Rute Minimum Truk Pengangkut Sampah pada Kecamatan Puwatu menggunakan Metode Algoritme Bellman-Ford. Algoritme Bellman Ford digunakan untuk menghitung jarak terpendek dari satu titik pada grafik berbobot. Maksudnya adalah Algoritme Bellman-Ford menghitung jarak terpendek dari semua titik. Adapun langkah- terdapat pada Gambar 1. Pada peta kecamatan Puuwatu terdapat tujuh jalan yang akan diteliti dan dituangkan ke dalam bentuk graf. Adapun gambarnya sebagai berikut.

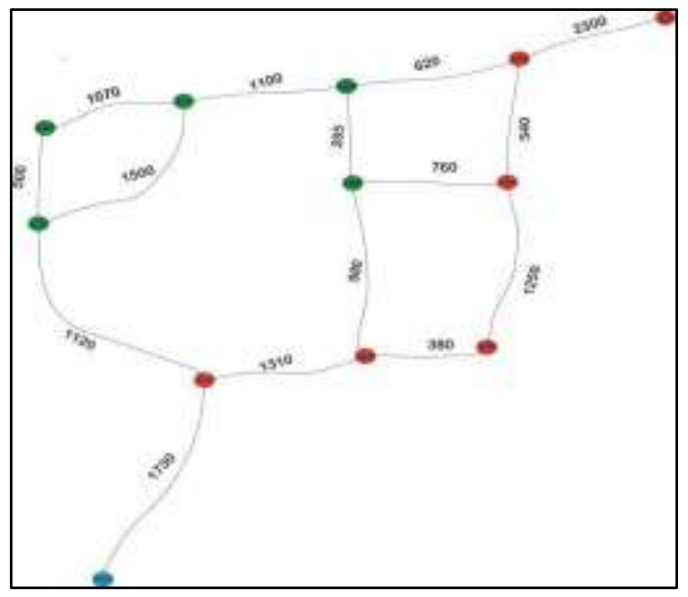

Gambar 3. Rute Awal Dinas Lingkungan Hidup Kota Kendari

3-6 : Anonim Street; Titik 5-8 - 9 : Jl. Pattimura; Titik $8-10$ : Jl. Ratnasari; Titik $9-10-11-7-4$ : Jl. Chairil Anwar; Titik $11-12$ : Jl. TPA Puwatu

langkahnya berdasarkan prosedur penelitian sebagai berikut.

a. Menentukan titik awal dan menguraikan semua titik maupun sisi

b. Memberi nilai untuk titik awal $=0$ dan titik lainnya dengan nilai tak hingga $(\infty)$

c. Memulai iterasi terhadap semua titik yang dimulai dengan titik asal,untuk menentukan jarak dari semua titik yang berhubungan dengan titik asal dengan cara

Jika jarak V lebih besar dari jarak U + bobot UV maka jarak V diisi dengan jarak U + bobot UV. Dimana: $\mathrm{U}=$ titik asal $\mathrm{V}=$ titik tujuan $\mathrm{UV}=$ sisi yang menghubungkan $\mathrm{U}$ dan $\mathrm{V}$. Langkah ini digunakan agar semua titik tekunjungi. Berikut penyelesaian secara manual. 


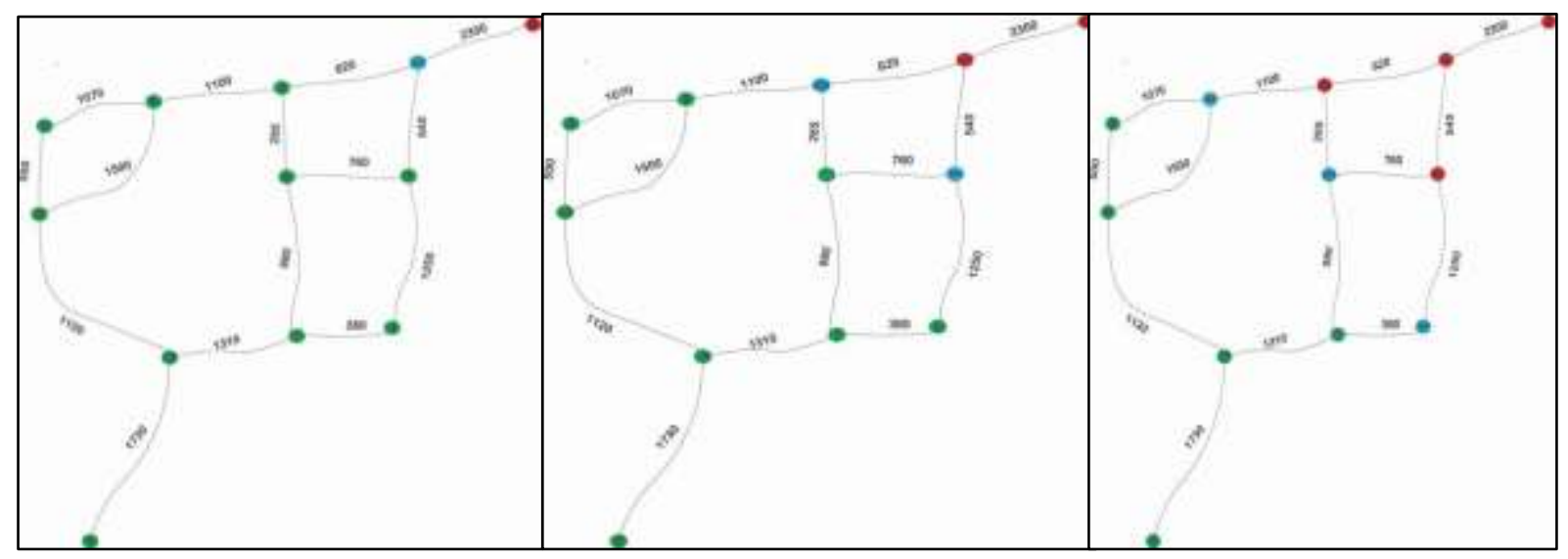

(a)

(b)

(c)

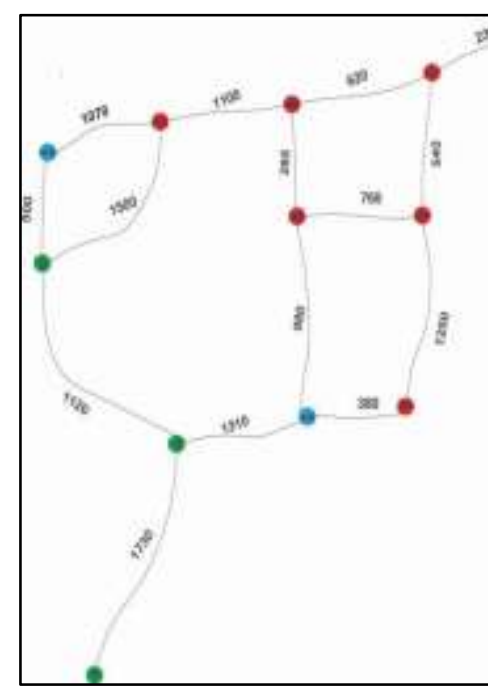

(d)

(e)

(f)

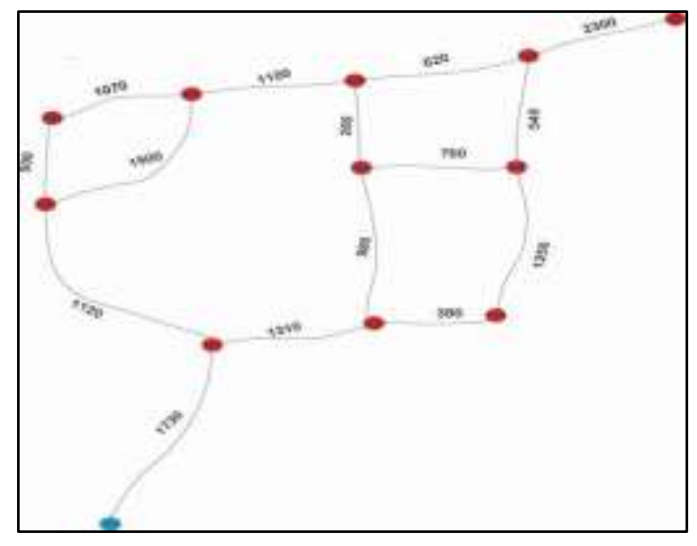

(g)

Gambar 4. Pemeteraan posisi sesuai interasi (a) interasi 1, (b) interasi 2, (c) interasi 3, (d) iterasi 4, (e) iterasi 5, (f) iterasi 6, (g) iterasi 7. 


\begin{tabular}{|c|c|c|c|}
\hline $\begin{array}{l}\text { Iterasi } 1: \\
\begin{aligned} 0-2 & =0+2300 \\
& =2300 \mathrm{~m}\end{aligned}\end{array}$ & $\begin{array}{l}\text { Iterasi } 2 \text { : } \\
\begin{aligned} 2-5= & 2300+620 \\
& =2920 \mathrm{~m}\end{aligned} \\
\begin{aligned} 2-3= & 2300+540 \\
& =2840 \mathrm{~m}\end{aligned}\end{array}$ & $\begin{array}{l}\text { Iterasi } 3: \\
\begin{aligned} 5-8= & 2920+1100 \\
= & 4020 \mathrm{~m} \\
5-6= & 2920+285 \\
& =3205 \mathrm{~m} \\
3-4= & 2840+1250 \\
= & 4090 \mathrm{~m}\end{aligned}\end{array}$ & $\begin{array}{l}\text { Iterasi } 4: \\
8-9=4020+1070 \\
=5090 \mathrm{~m} \\
\begin{aligned} 6-7= & 3205+980 \\
& =4185 \mathrm{~m}\end{aligned}\end{array}$ \\
\hline
\end{tabular}

\begin{tabular}{l|l|l} 
Iterasi $5:$ & Iterasi $6:$ & Iterasi $57:$ \\
$\begin{aligned} 8-10=4020+1500 \\
=5520 \mathrm{~m}\end{aligned}$ & $\begin{array}{c}7-11=4185+1310 \\
=5495 \mathrm{~m}\end{array}$ & $\begin{array}{c}11-12=5495+1730 \\
=7225 \mathrm{~m}\end{array}$
\end{tabular}

Dari ketujuh iterasi yang ada terdapat beberapa warna yang dijadikan sebagai node rute perjalanan. Warna tersebut meliputi hijau, merah dan biru dimana warna hijau digunakan sebagai node untuk menandai rute yang belum dilintasi. Warna merah digunakan sebagai node acuan. Sedangkan warna biru digunakan sebagai node akhir yang telah diperoleh dari penjumlahan node awal dan bobot antar node.

Berdasarkan hasil investigasi yang telah dilakukan terdapat tujuh nama jalan yang diteliti di kecamatan Puuwatu, kemudian di interpretasikan ke dalam bentuk graf dimana terdapat 12 titik yang dicari rute terpendeknya. Dua belas titik tersebut merupakan batasbatas jalan yang dimana bias dilihat pada Gambar 4 sebagai rute jalan kecamatan Puwatu. Dari hasil penelitian untuk mencari rute terpendek melalui Algoritme Bellman-Ford yaitu dengan menggunakan cara manual. Penyelesaian pada kasus ini menggunakan Algoritme Bellman-Ford menggunakan beberapa tahap. Namun, sebelum menyelesaikan kasus ini terlebih dahulu mencari jarak dari masing-masing titik. Untuk menghitung jarak dari masing-masing titik menggunakan aplikasi MapitGIS.

Mapit GIS adalah salah satu aplikasi yang digunakan untuk yang mengukur jarak antar setiap titik yang tersedia (Ariwibowo dlk. 2020). Dengan menggunakan aplikasi ini, setiap batas-batas jalan dapat terlihat layaknya google Maps kemudian didapatkan jarak antar setiap titik dengan cara menghubungkan setiap titik ke titik lainnya dilihat bahwa rute pengangkutan sampah yang biasa diterapkan oleh Dinas Lingkungan Hidup Kota Kendari yaitu melalui titik 0-2-3-4-7-11-12. Rute pengangkutan sampah tersebut jika dihitung secara manual yaitu berjarak $7510 \mathrm{~m}$ sedangkan jika menggunakan Algoritma Bellmand-Ford rute pengangkutan sampah menuju TPA yaitu melalui titik 02-5-6-7-11-12 berjarak $7225 \mathrm{~m}$. Hal ini menunjukkan bahwa dengan menggunakan Algoritma Bellmand-Ford rute yang didapatkan lebih minimum dibandingkan dengan rute yang diterapkan oleh Dinas Lingkungan Kota Kendari.

Rute pengangkutan sampah yang didapatkan melalui Algoritma Bellmand-Ford lebih minimum dibandingkan rute yang diterapkan saat ini oleh Dinas Lingkungan Hidup Kota Kendari. Rute yang didapatkan melalui Algoritma Bellmand-Ford dapat menghemat perjalanan hingga 3,8\% sehingga rute pengangkutan sampah lebih optimal dan efisien.

\section{KESIMPULAN DAN SARAN}

Berdasarkan hasil penelitian dan pembahasan dapat disimpulkan bahwa: (1) Pada penelitian ini terdapat 7 nama jalan yang diteliti di kecamatan Puuwatu kemudian dituangkan kedalam bentuk graf. Pada graf yang terbentuk terdapat 12 titik yang dicari rute minimumnya,dimana 12 titik tersebut merupakan batasbatas jalan yang ada di kecamatan Puuwatu. Untuk menentukan rute minimum menggunakan Algoritma Bellmand- Ford dilakukan dengan cara menentukan titik awal kemudian menghubungkan titik-titik yang terhubung dari titik awal tersebut, lalu setiap titik diisi dengan jarak terpendek dari titik awal yang telah di tentukan. Perhitungan selesai jika semua titik sudah saling terhubung dengan jarak terpendek; (2) Untuk menentukan studi kasus di kecamatan Puuwatu dalam mencari rute minimum pengangkutan sampah menuju tempat pembuangan akhir(TPA) membutuhkan 7 iterasi dari 12 titik yang dicari rute minimumnya sehingga semua titik terhubung. Rute pengangkutan sampah yang diterapkan saat ini adalah $7.510 \mathrm{~m}$ sedangkan setelah dihitung menggunakan Algoritma Bellmand-Ford menjadi $7.225 \mathrm{~m}$. Kajian ini termasuk penelitian pendahuluan sebagai landasan pengembanagn kajian selanjutnya.

\section{REFERENCES}

Aji, A. (2017). Optimasi Jalur Tercepat Dengan Menggunakan Modifikasi Algoritma Bellman 
Ford (Studi Kasus Lintas Antar Kecamatan Kota Malang). Jurnal EECCIS, 9(2), 168-172.

Ariwibowo, M. M., Suharno, S., \& Wahyuni, W. (2020). Efektivitas Pemanfaatan Aplikasi LOCUS GIS dan MAPIT GIS Untuk Pengumpulan Data Pendaftaran Tanah. Jurnal Tunas Agraria, 3(1 Jan), 116-144.

Azdy, R. A., \& Darnis, F. (2019). Implementasi Bellman-Ford untuk Optimasi Rute Pengambilan Sampah di Kota Palembang. Jurnal Nasional Teknik Elektro dan Teknologi Informasi (JNTETI), 8(4), 327-333.

Daniel, Farida., \& Prida, N, L, T,. (2019). Teori graf. Yogyakarta: $\mathrm{CV}$ budi Utama.

Hamdi, S., \& Prihandoko, P. (2018). Analisis Algoritma Dijktra dan Algoritma Bellman-Ford Sebagai Penentuan Jalur Terpendek Menuju Lokasi Kebakaran (Studi Kasus: Kecamatan Praya Kota). Energy, 8(1), 26-32.

Lestari, S. (2018). Perbandingan Algoritma FloydWarshall dan Bellman-Ford dalam Pencarian Jarak Terpendek Antar ATM di Kota Tebing Tinggi.

Munir, R. (2009). Matematika Diskrit. Bandung: Informatika,

Nugraha, D. W. (2011, September). Aplikasi algoritma prim untuk menentukan minimum spanning tree suatu graf berbobot dengan menggunakan pemrograman berorientasi objek. In FORISTEK: Forum Teknik Elektro dan Teknologi Informasi (Vol. 1, No. 2).

Rasdiana. (2015). Aplikasi Algoritma Bellman-Ford dalam Meminimumkan Rute Perjalanan Tukang Bentor di Kecamatan Biringkanaya. Makassar : UIN Alauddin Makassar.

Yudi, R. (2009). Algoritma Dijkstra dan Bellman-Ford dalam Pencarian Jalur Terpendek. Makalah IF2091 Shortest Path Algorithm. Diakses Tanggal $25 \quad$ Maret 2020. https://informatika.stei.itb.ac.id/ rinaldi.munir/ Matdis/2009/2010/Makalah0910/MakalahStrukd is0910-082.pdf

Pramudita, R., \& Safitri, N. (2018). Algoritma BellmanFord Untuk Menentukan Jalur Tercepat Dalam Sistem Informasi Geografis. PIKSEL: Penelitian Ilmu Komputer Sistem Embedded and Logic, 6(2), 105-114.

Prasetyo, A. (2017). Optimasi Jalur Tercepat Dengan Menggunakan Modifikasi Algoritma Bellman Ford (Studi Kasus Lintasan Antar Kecamatan Kota Malang) (Doctoral dissertation, Universitas Brawijaya).
Sulaiman, O. K., Siregar, A. M., Nasution, K., \& Haramaini, T. (2018). Bellman Ford algorithmIn Routing Information Protocol (RIP). In $J$. Phys. Conf. Ser (Vol. 1007, No. 1). 